\title{
ANALISA PENGENDALIAN KUALITAS RESIN ABC MENGGUNAKAN SIX SIGMA DI PT. PARDIC JAYA CHEMICALS
}

\author{
Tri Widodo, Hari Priyadi \\ Program Studi Teknik Industri, Fakultas Teknik, \\ Universitas Muhammadiyah Tangerang \\ Jl. Perintis Kemerdekaan I/33, Cikokol, Kota Tangerang
}

\begin{abstract}
ABSTRAK
Perkembangan teknologi di dunia bisnis dan perdagangan membuat persaingan menjadi ketat dan tajam. Dalam usahanya untuk memenuhi kepuasan konsumen yang makin tinggi, maka perusahaan harus dapat menentukan faktor kualitas yang diminta oleh konsumen, selain faktor harga, design, dan faktor lainnya.Salah satu metode yang dapat dilakukan perusahaan untuk selalu meningkatkan kualitas produksi adalah dengan menggunakan metode Six Sigma. Six Sigma merupakan pengendalian kualitas yang targetnya yaitu 3,4 DPMO atau 3,4 cacat per sejuta kesempatan. Dengan adanya target six sigma yang 3,4 DPMO maka dapat dikatakan realitas untuk dapat dicapai dari pengendalian kualitas yang berdasar pada zero defect. Pengendalian kualitas yang dipakai dalam penelitian ini menggunakan pendekatan six sigmadengan metodologi DMAIC (Define, Measure, Analyze, Improve, Control), yang dilakukan di tiap proses produksi tetapi sebelum melaksanakan pengendalian kualitas dengan metode sixsigmaperlu adanya rencana agar pelaksanaan six sigma dapat sukses diterapkan.Pengendalian kualitas dibutuhkan PT. Pardic Jaya Chemicals untuk tetap menjaga proses produksi menjadi aliran proses yang kuat dan handal sehingga pencapaian level sigma sebesar 3,46 dan DPMO sebesar 25514,4 dapat lebih ditingkatkan serta tidak ada lagi hasil produksi yang cacat atau dengan kata lain tidak ada lagi kerugian bagi perusahaan karena produk cacat.
\end{abstract}

Kata kunci:Teknologi, Six Sigma, DPMO,zero defect, DMAIC(Define, Measure, Analyze, Improve, Control).

\section{PENDAHULUAN}

PT. Pardic Jaya Chemicals adalah salah satu perusahaan resin sintetis yang selalu berusaha menghasilkan resin sintetis yang sesuai dengan standar demi memuaskan pelanggan. Pada kenyataannya, masih terdapat produk yang defect/cacat. Hal ini tentunya tidak sesuai dengan target peru-sahaan yang menginginkan hasil produksi yang sempurna demi menghadapi persaingan dunia bisnis yang semakin ketat.

Salah satu metode yang dapat digunakan untuk mengendalikan kualitas dan meng- atasi cacat produk yang banyak adalah metode six sigma. Melalui penekanan pada kemampuan proses (Process Capability), industri dapat mengharapkan 3.4 kegagalan per sejuta kesempatan (DPMO - Defects Per Million Opportunities). Six sigma sendiri merujuk kepada target kinerja operasi yang diukur secara statistik dengan hanya 3,4 cacat (defect) untuk setiap juta aktivitas atau peluang. Dengan kata lain, six sigma adalah sebuah konteks yang didalamnya kita akan dapat mengintegrasikan banyak "praktik terbaik" serta konsep manajemen yang 
berharga tapi sering kali tidak berkaitan, mencakup pemikiran sistem, perbaikan terus menerus, knowledge Management, mass customization, dan manajemen berbasis aktivitas (activity-based management) (Pande dkk, 2002:82). Tujuan penelitian ini adalah untuk mengetahui faktor-faktor penyebab defect yang terjadi pada produk resin $A B C$ dan mengetahui prioritas usulan perbaikan yang dapat digunakan untuk mengurangi jumlah defect pada resin $\mathrm{ABC}$.

\section{METODE PENELITIAN}

Metode yang digunakan dalam penelitian ini adalah six sigma. Aplikasi six sigma berfokus pada cacat dan variasi, dimulai dengan mengidentifikasi unsur-unsur kritis terhadap kualitas (Critical to Quality - CTQ) dari suatu proses. Six sigma menganalisa kemampuan proses dan bertujuan menstabilkannya dengan cara mengurangi atau menghilangkan variasi-variasi. Langkah mengurangi cacat dan variasi dilakukan secara sistematis dengan mendefinisikan, mengukur, menganalisa, memperbaiki, dan mengendalikannya. Langkah penelitian yang dilakukan adalah:

1. Survey pendahuluan yang dilakukan pada PT Pardic Jaya Chemicals untuk mengetahui kondisi umum perusahaan;

2. Identifikasi masalah dengan membahas masalah yang terkait atribut produk yang tidak sesuai dengan spesifikasi;

3. Studi Literatur yang dilakukan dengan cara mempelajari buku dan jurnal ilmiah untuk mendapatkan referensi terkait dengan topik yang dibahas pada penelitian ini;

4. Pengumpulan data yang dilakukan untuk mendapatkan data mengenai jumlah produk defect serta tipe defect;

5. Analisa yang dilakukan melalui tahap define, measure, analyze, dan improve menggunakan data yang telah diperoleh dari tahap pengumpulan data;

6. Pembahasan yang dilakukan untuk me- nguraikan lebih rinci terkait hasil yang diperoleh dari tahap analisa;

7. Kesimpulan yang merupakan jawaban atas permasalahan yang ada. Analisis pada penelitian ini dilakukan dengan menggunakan metode six sigma melalui tahap sebagai berikut:

\subsection{Define}

Pada tahap ini PT. Pardic Jaya Chemicals mendefinisikan masalah-masalah kualitas produk resin $A B C$ dengan cara menghitung persentase produk cacat terhadap jumlah produksi pada bulan Januari sampai September 2014. Pada tahap ini ditentukan proporsi defect yang menjadi penyebab paling signifikan terhadap adanya kerusakan produk. Langkah-langkah yang dilakukan pada tahap define ini adalah sebagai berikut:

a. Mendefinisikan kriteria pemilihan proyek yang ada di perusahaan PT. Pardic Jaya Chemicals.

Pada tahap ini PT. Pardic Jaya Chemicals mendefinisikan masalah-masalah kualitas produk resin $A B C$, proses produksi dengan cara menghitung persentase produk cacat terhadap jumlah produksi pada bulan Januari sampai September 2014.

Prosentase produk cacat $=\frac{\text { jumlan produk cacat }}{\text { jumlah produk }} \times 10036$

b. Mendefinisikan peran orang-orang yang terlibat dalam memproduksi resin $A B C$ di PT. Pardic Jaya Chemicals.

Jabatan yang berkaitan dengan masalah produksi adalah pada jabatan bagian produksi. Permasalahan yang timbul seperti kurangnya pengawasan dalam memproduksi resin $A B C$, hal ini disebabkan karena mereka masih memiliki sedikit pengetahuan atau wawasan yang lebih luas mengenai pengendalian kualitas, maka salah satu cara untuk menanganinya yaitu semua individu yang terlibat pada bagian produksi diberikan sebuah 
training dan penyuluhan mengenai pengendalian kualitas.

c. Mendefinisikan proses kunci beserta pelanggan dari produk resin $A B C$ dengan metode Six Sigma

Dengan membandingkan standarisasi yang telah ditetapkan perusahaan yaitu tidak lebih $1 \%$ dari jumlah produk pada proses produksi dengan hasil perhitungan persentase produk cacat resin $A B C$ terhadap jumlah produk resin pada bulan Januari sampai September 2014.

\subsection{Measure}

Langkah-langkah yang dilakukan pada tahapmeasure ini adalah sebagai berikut:

a. Menetapkan karateristik kualitas (CTQ) kunci

Langkah ini menetapkan karateristik kunci apa saja yang dapat menyebabkan suatu produk tidak memenuhi harapan pelanggan.

b. Melakukan pengukuran baseline kinerja

Pada langkah ini dilakukan pengukuran tingkat kinerja perusahaan sebelum proyek six sigma berlangsung dapat dilihat. Langkahlangkah untuk melakukan pengukuran baseline kinerja adalah sebagai berikut:

a. Menetapkan periode waktu yang akan diuji

b. Menuliskan jumlah produk yang akan diperiksa selama periode no.1 pada kolom tabel (B)

C. Menuliskan jumlah produk cacat pada kolom tabel (C)

d. Menuliskan jumlah CTQ potensial penyebab kecacatan produk pada tabel (D)

e. Menghitung dan menuliskan DPMO pada kolom tabel $\mathrm{D}$ dengan menggunakan

$$
\text { rumus:DPMO }=\frac{\mathrm{C}}{\mathrm{B} \times \mathrm{D}} \times 1.000 .000
$$

f. Mengkonversi DPMO menjadi nilai sigma, dengan menggunakan tabel Konversi Hasil Bebas Cacat ke Nilai Sigma dan DPMO

\subsection{Analyze}

Langkah-langkah yang dilakukan pada tahap analyze adalah sebagai berikut:

a. Melakukan analisis kapabilitas proses Pada langkah ini dilakukan perhitungan CTQ potensial untuk mengetahui CTQ potensial tertinggi yang menyebabkan terjadinya produk cacat. Langkah yang ditempuh untuk menghitung CTQ potensial tertinggi yaitu:

1. Menghitung frekuensi dari setiap СTQ yang kemudian hasilnya dituliskan ke dalam tabel

2. Menggambarkan hasil perhitungan ke dalam Diagram Pareto

b. Mengidentifikasi sumber-sumber penyebab produk cacat

Pada langkah ini diidentifikasi sumbersumber penyebab terjadinya produk cacat. Oleh karena itu digunakan diagram sebab akibat atau diagram Ishikawa (Fish Bone) yang sering disebut diagram tulang ikan. Dalam penelitian ini penyebab kerusakan produk hanya ditinjau dari:

1. Man/manusia yang terlibat langsung dalam proses produksi

2. Material/bahan baku yang digunakan dalam proses produksi

3. Machine/mesin dan peralatan yang digunakan dalam proses produksi

4. Method/metode yang digunakan dalam proses produksi

5. Media/lingkungan yang terlibat langsung atau yang tidak langsung dalam proses produksi

\subsection{Improve}

Menetapkan rencana tindakan (actionplan) untuk melaksanakan peningkatan kualitas six sigma. Rencana mendeskripsikan tentang alokasi sumber daya serta prioritas dan alternatif yang dilakukan dalam implementasi dari rencana itu. Perancangan pada tahap improve dilakukan dengan cara melalui tahap-tahap merancang metode $5 \mathrm{~W}-1 \mathrm{H}$ 
(What-tujuan, Why-alasan kegunaan, Wherelokasi, When-kapan, Who-orang, dan Howmetode).

a. Improve pada faktorMan: ditentukan apakah tujuan improve pada faktor Man, alasan kegunaannya, lokasi, sekuens, dan bagaimana caranya.

b. Improve pada faktor Machine: ditentukan apakah tujuan improve pada faktor $\mathrm{Ma}$ chine, alasan kegunaannya, lokasi, sekuens, dan bagaimana caranya.

c. Improve pada faktor Material: ditentukan apakah tujuan improve pada faktor $\mathrm{Ma}$ terial, alasan kegunaannya, lokasi, sekuens, dan bagaimana caranya.

d. Improve pada faktor Method: ditentukan apakah tujuan improve pada faktor $\mathrm{Me}$ thod, alasan kegunaannya, lokasi, sekuens, dan bagaimana caranya.

e. Improve pada faktor Media: ditentukan apakah tujuan improve pada faktor Media, alasan kegunaannya, lokasi, sekuens, dan bagaimana caranya.

\subsection{Control}

Perancangan pada tahapcontrol dilakukan dengan merancang hasil-hasil peningkatan kualitas yang akan kemudian akan mengintegrasikan hasil six sigma ke cara-cara praktek bisnissehingga tercapai pengendalian kualitas perusahaan.

\section{ANALISA \& PEMBAHASAN}

\subsection{Tahap Define}

Fase ini terkait dengan identifikasi proses atau produk yang membutuhkan perbaikan. Tujuan yang akan dicapai adalah mengurangi jumlah defect pada hasil produksi. Defect yang menjadi fokus perbaikan adalah produk yang mempunyai prosentase defect paling besar atau paling dominan. Yang pertama dilakukan adalah mencari produk-produk yang menyebabkan kerugian terbesar karena terjadi defect.

\begin{tabular}{|c|c|c|}
\hline No & ProductType & Quantities (kg) \\
\hline 1 & Acrydic & 167000 \\
\hline 2 & Polylite & 310000 \\
\hline 3 & Beckosol & 98560 \\
\hline 4 & Burnock & 325000 \\
\hline 5 & Dicdry & 285000 \\
\hline 6 & Precom & 20000 \\
\hline 7 & Styresol & 15000 \\
\hline & Total & $\mathbf{1 2 2 0 5 6 0}$ \\
\hline
\end{tabular}

Dari tabel diatas terlihat produk Burnock adalah produk yang kuantiti produksinya paling besar.

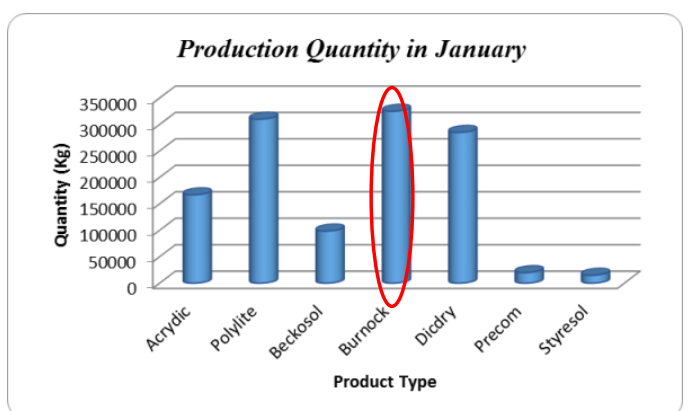

Dari tipe produk burnock ada beberapa macam resin yang diproduksi dan beberapa diantaranya terjadi defect. Hal ini terlihat pada grafikdibawah ini:

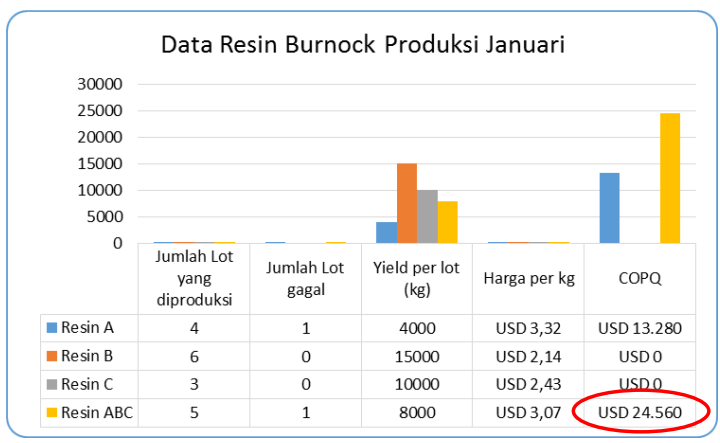

Dari tabel diatas dapat diketahui bahwa produk tipe burnock yang menyebabkan kerugian terbesar adalah kegagalan produksi pada jenis resin $A B C$ yang mempunyai tingkat COPQ terbesar yaitu USD 24.560 selama produksi bulan Januari saja. Bisa dibayangkan bila kegagalan tersebut tidak segera ditindaklanjuti maka kerugian perusahaan akan semakin bertambah besar yang dikarenakan produk cacat. Berdasarkan data diatas maka 
diambil data dari total jumlah produksi yang diperiksa, banyaknya hasil produksi yang tidak memenuhi standar, dan persentase produk yang tidak memenuhi standar produksi resin $A B C$ selama periode Januari sampai September 2014 dan datanya adalah sebagai berikut:

\begin{tabular}{|c|c|c|c|}
\hline Bulan & $\begin{array}{c}\text { Jumlah item resin } \\
\text { ABC yang diperiksa }\end{array}$ & $\begin{array}{c}\text { Jumlah item yang tidak } \\
\text { memenuhi standar }\end{array}$ & $\begin{array}{c}\% \text { Tingkat } \\
\text { produk yang } \\
\text { tidak } \\
\text { memenuhi } \\
\text { standar }\end{array}$ \\
\hline Januari & 45 & 1 & $2,2 \%$ \\
\hline Februari & 36 & 1 & $2,8 \%$ \\
\hline Maret & 36 & 2 & $5,6 \%$ \\
\hline April & 54 & 2 & $3,7 \%$ \\
\hline Mei & 45 & 1 & $2,2 \%$ \\
\hline Juni & 54 & 1 & $1,9 \%$ \\
\hline Juli & 36 & 1 & $2,8 \%$ \\
\hline Agustus & 54 & 2 & $3,7 \%$ \\
\hline September & 36 & 1 & $2,8 \%$ \\
\hline Rata-rata & 44,0 & 1,3 & $3,1 \%$ \\
\hline
\end{tabular}

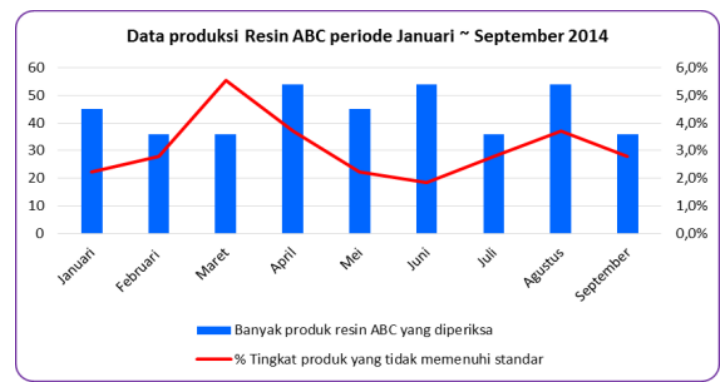

Terlihat bahwa terjadi defect pada resin $A B C$ rata-rata sebanyak 1,3\% tiap bulan. Hal ini pasti sangat tidak diinginkan oleh perusahaan karena menjadi kerugian yang sangat besar bagi perusahaan apalagi dilihat dari nilai uang yang dikeluarkan perusahaan. Sedangkan flow proses dapat dilihat dari diagram SIPOC berikut:

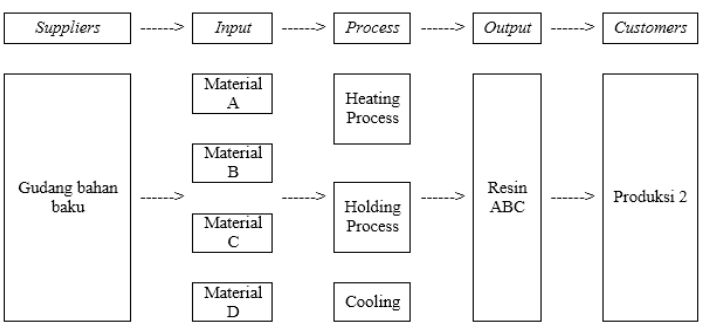

\subsection{Tahap Measure}

Measuremerupakan tahap pengevaluasian sistem pengukuran dan menaksir kemampuan baseline kinerja (output) dari perusahaan PT. Pardic Jaya Chemicals. Tahap measure ini terdiri dari dua langkah yaitu:

1. Menetapkan karakteristik kualitas kunci (CTQ)

Karakteristik-karakteristik kunci yang dapat menyebabkan hasil produksi resin $A B C$ tidak dapat memenuhi harapan pelanggan adalah sebagai berikut:
a. $\mathrm{OH}$-Valuetinggi
b. Colortinggi
c. Water Content tinggi

\begin{tabular}{|c|c|c|c|c|}
\hline Bulan & $\begin{array}{l}\text { Banyak item } \\
\text { resin } A B C \text { yang } \\
\text { diperiksa }\end{array}$ & $\begin{array}{l}\text { Jumlah item resin } \\
\text { ABC cacat }\end{array}$ & $\begin{array}{c}\text { Banyak } \\
\text { CTQ } \\
\text { potensial } \\
\text { penyebab } \\
\text { kecacatan }\end{array}$ & $\begin{array}{c}\text { Deskripsi } \\
\text { CTQ } \\
\text { potensial }\end{array}$ \\
\hline Januari & 45 & 1 & 1 & $\begin{array}{c}\text { OH-Value } \\
\text { tinggi }\end{array}$ \\
\hline Februari & 36 & 1 & 1 & $\begin{array}{c}\text { OH-Value } \\
\text { tinggi }\end{array}$ \\
\hline Maret & 36 & 2 & 2 & $\begin{array}{l}\text { OH-Value } \\
\text { tinggi, } \\
\text { Color } \\
\text { tinggi }\end{array}$ \\
\hline April & 54 & 2 & 1 & $\begin{array}{c}\text { OH-Value } \\
\text { tinggi }\end{array}$ \\
\hline Mei & 45 & 1 & 1 & $\begin{array}{c}\text { OH-Value } \\
\text { tinggi }\end{array}$ \\
\hline Juni & 54 & 1 & 1 & $\begin{array}{c}\text { OH-Value } \\
\text { tinggi }\end{array}$ \\
\hline Juli & 36 & 1 & 1 & $\begin{array}{c}\text { OH-Value } \\
\text { tinggi }\end{array}$ \\
\hline Agustus & 54 & 2 & 2 & $\begin{array}{l}\text { OH-Value } \\
\text { tinggi, } \\
\text { Water } \\
\text { content } \\
\text { tinggi }\end{array}$ \\
\hline September & 36 & 1 & 1 & $\begin{array}{c}\text { OH-Value } \\
\text { tinggi }\end{array}$ \\
\hline
\end{tabular}

Dari tabel diatas dapat diketahui bahwa ada tiga karakteristik kualitas kunci (CTQ) dalam proses produksi resin $A B C$ selama periode Januari sampai dengan September, banyak CTQ potensial yang terjadi didominasi oleh kecacatan karena $\mathrm{OH}$-Value tinggi. Hal ini dapat terlihat pada bulan Januari ada satu cacat karena $\mathrm{OH}$-Value tinggi, bulan Februari ada satu kecacatan potensial $\mathrm{OH}$ Value tinggi, bulan Maret ada dua kecacatan potensial $\mathrm{OH}$-Value tinggi dan Color tinggi, bulan April ada satu kecacatan potensial $\mathrm{OH}$ Value tinggi, bulan Mei ada satu kecacatan potensial $\mathrm{OH}$-Value tinggi, bulan Juni ada satu kecacatan potensial $\mathrm{OH}$-Valuetinggi, bulan Juli ada satu kecacatan potensial $\mathrm{OH}$ Valuetinggi, bulan Agustus ada dua kecacatan potensial $\mathrm{OH}$-Value tinggi dan Water content tinggi, sedangkan bulan September ada satu kecacatan potensial $\mathrm{OH}$-Value tinggi. 
2. Melakukan pengukuran kinerja output (produk resin $\mathrm{ABC}$ )

Pengukuran kinerjaoutput dilakukan dengan cara menghitung data hasil pemeriksaan hasil proses pembuatan resin $A B C$ serta menghitung DPMO dan nilai sigma PT. Pardic Jaya Chemicals, seperti tabel berikut:

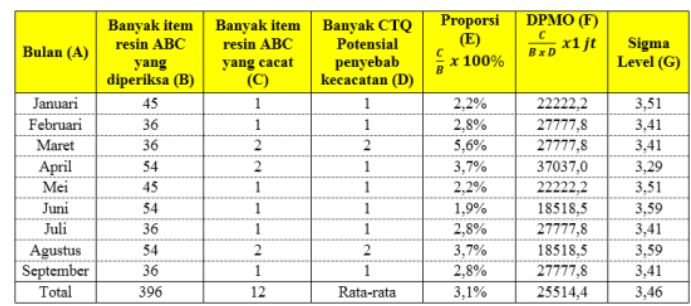

Tabel Konversi Sigma

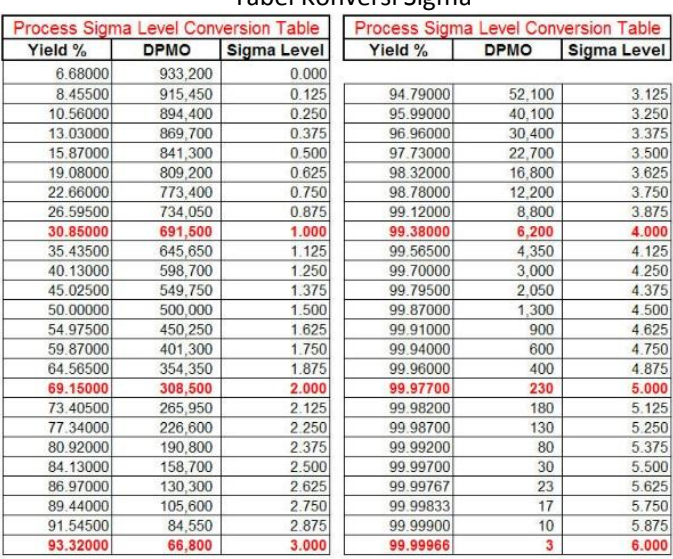

Berdasarkan dari hasil perhitungan diatas, maka dapat dinyatakan bahwa PT. Pardic Jaya Chemicals memiliki tingkat sigma sebesar 3,46 dengan DPMO rata-rata sebesar 25514,4 per sejuta produk resin ABC. Perusahaan dapat melakukan pengukuran output tentang jenis kecacatan yang ditentukan sehingga dapat diketahui kapabilitas sigma dan DPMO perusahaan saat ini, kemudian perusahaan harus melakukan perbaikan-perbaikan untuk mengurangi jumlah kecacatan produk dengan metode six sigma sehingga dapat mengurangi jumlah defect/cacat yang sering terjadi.

\subsection{TahapAnalyze}

Tahap analyze dilakukan untuk mengidentifikasi masalah dan menemukan sumber penyebab masalah kualitas. Tahap ini terdiri atas dua langkah yaitu:

1. Analisa stabilitas dan kapabilitas (kemampuan) proses

Dalam melakukan analisis kapabilitas proses terdapat dua langkah berikut, yaitu:

a) Menghitung frekuensi dari setiap CTQ yang kemudian hasilnya dituliskan ke dalam tabel, sebagai berikut:

\begin{tabular}{|c|l|c|c|c|c|}
\hline No & Jenis Kecacatan & $\begin{array}{c}\text { Frekuensi } \\
\text { Kecacatan }\end{array}$ & $\begin{array}{c}\text { Frekuensi } \\
\text { Kumulatif } \\
\text { Kecacatan }\end{array}$ & $\begin{array}{c}\text { Persentase } \\
\text { dari total } \\
\text { cacat (\%) }\end{array}$ & $\begin{array}{c}\text { Persentase } \\
\text { Kumulatif } \\
(\%)\end{array}$ \\
\hline 1 & OH Value Tinggi & 10 & 10 & 83,33 & 83,33 \\
\hline 2 & $\begin{array}{l}\text { Water Content } \\
\text { Tinggi }\end{array}$ & 1 & 11 & 8,33 & 91,67 \\
\hline 3 & Color Tinggi & 1 & 12 & 8,33 & 100,00 \\
\hline & Total & 12 & & 100,00 & \\
\hline
\end{tabular}

b) Menggunakan hasil perhitungan ke dalam diagram Pareto

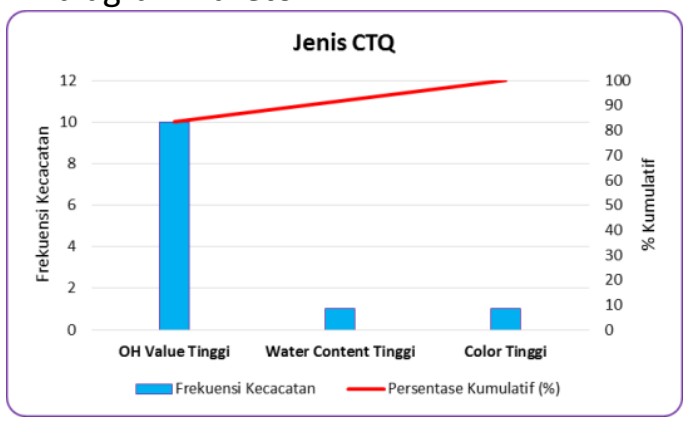

c) Data dan controlchart proses
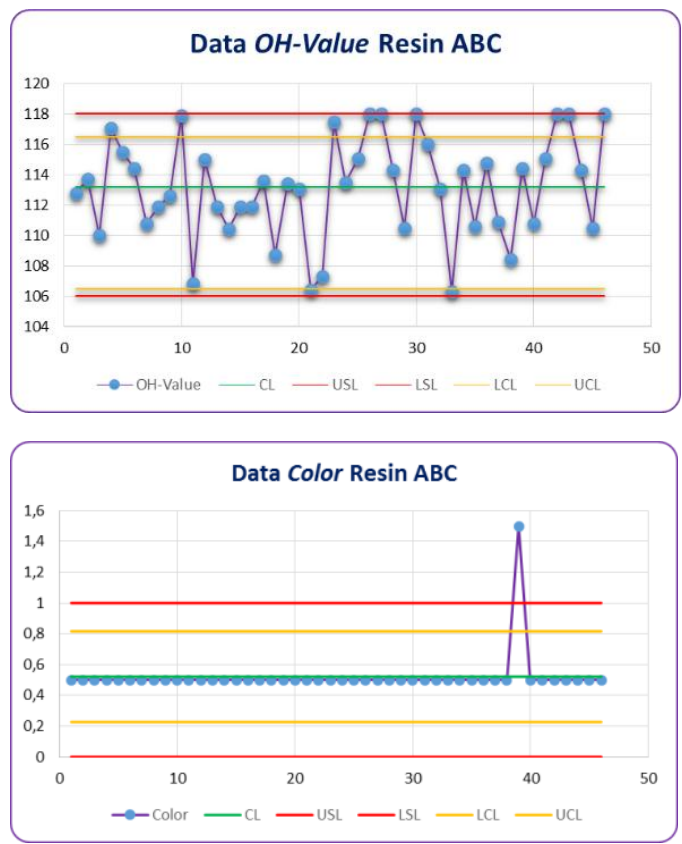


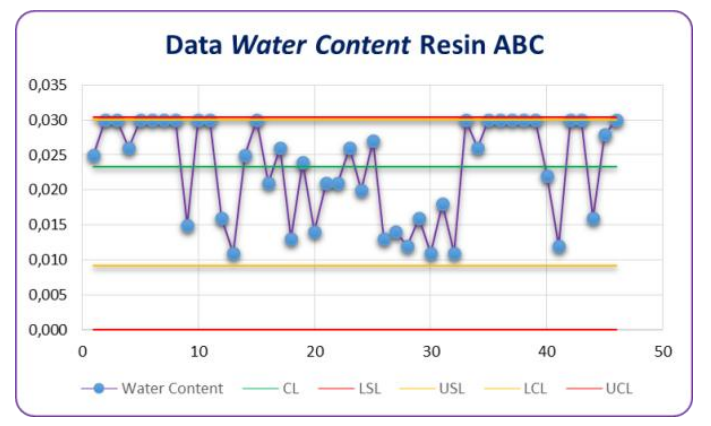

d) Menghitung Kapabilitas Proses (Cp) \& Cpk menggunakan software Minitab
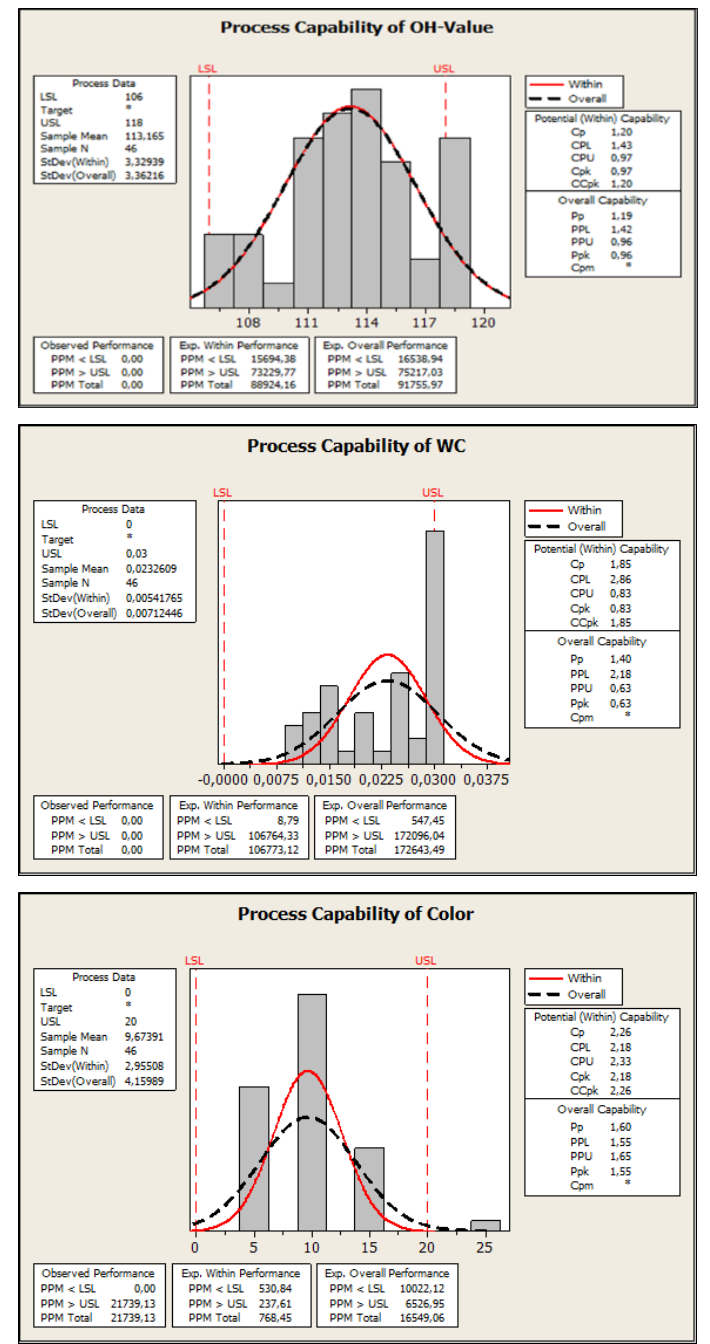

Berdasarkan tabel dan gambar diatas, dapat diketahui rincian tidak terpenuhinya jenis CTQ yang pada akhirnya mengakibatkan terjadinya produk cacat di PT. Pardic Jaya Chemicals. Dari diagram pareto dapat langsung dilihat bahwa jenis dan jumlah kecacatan terbesar pada resin $A B C$ yaitu diakibatkan oleh hasil $\mathrm{OH}$-Value yang tinggi sebesar 10 kecacatan sedangkan tabel 4.4 dapat diketahui jumlah persentase dari kecacatan sebesar $83,33 \%$ dari total kecacatan. Jenis kecacatan kedua adalah color tinggi sebanyak 1 kecacatan dengan persentase sebesar $8,33 \%$ dan jenis kecacatan ketiga adalah watercontent tinggi sebanyak 1 kecacatan dengan persentase sebesar 8,33\%. Pada kenyataannya di PT. Pardic Jaya Chemicals untuk proses pembuatan resin $X$ yang menggunakan resin $A B C$ sebagai bahan baku ada beberapa yang juga harus mengalami kegagalan karena penanganan yang kurang tepat. Maka dari itu dibutuhkan cara untuk menanggulangi jenis-jenis kecacatan yang terjadi pada resin $A B C$ agar tidak berlanjut pada terjadinya kecacatan lain saat proses pembuatan resin $\mathrm{X}$.

Sedangkan pada perhitungan menggunakan minitab dapat diketahui nilai $\mathrm{Cp} \& \mathrm{Cpk}$ dengan menggunakan software Minitab bahwa untuk $\mathrm{OH}$-Value mempunyai $\mathrm{Cp}$ dan $\mathrm{Cpk}$ sebesar 1,20 dan 0,97. Untuk watercontent sebesar 1,85 dan 0,83 sedangkan untuk color adalah sebesar 2,26 dan 2,18. Hal ini menandakan bahwa $\mathrm{OH}$-Value adalah proses yang paling tidak capablekarena $\mathrm{Cp}<1,33$.

2. Mengidentifikasi sumber-sumber dan akar masalah penyebab kualitas

\begin{tabular}{|c|c|c|c|c|c|c|c|}
\hline \multirow{2}{*}{ No } & \multirow{2}{*}{ Jenis Kecacatan } & \multicolumn{5}{|c|}{ Faktor Penyebab Kecacatan } & \multirow{2}{*}{ Total } \\
\hline & & Man & Material & Method & Machine & Media & \\
\hline \multirow{2}{*}{1} & \multirow{2}{*}{ OH-Value Tinggi } & 2 & 0 & 8 & 0 & 0 & 10 \\
\hline & & $16,67 \%$ & $0 \%$ & $66,67 \%$ & $0 \%$ & $0 \%$ & $83,33 \%$ \\
\hline \multirow{2}{*}{2} & \multirow{2}{*}{ Color Tinggi } & 0 & 1 & 0 & 0 & 0 & 1 \\
\hline & & $0 \%$ & $8,33 \%$ & $0 \%$ & $0 \%$ & $0 \%$ & $8,33 \%$ \\
\hline \multirow{2}{*}{3} & \multirow{2}{*}{$\begin{array}{l}\text { Water Content } \\
\quad \text { Tinggi }\end{array}$} & 0 & 0 & 1 & 0 & 0 & 1 \\
\hline & & $0 \%$ & $0 \%$ & $8,33 \%$ & $0 \%$ & $0 \%$ & $8,33 \%$ \\
\hline \multirow{2}{*}{\multicolumn{2}{|c|}{ Total }} & 2 & 1 & 9 & 0 & 0 & 12 \\
\hline & & $16,67 \%$ & $8,33 \%$ & $75,00 \%$ & $0,00 \%$ & $0,00 \%$ & $100 \%$ \\
\hline
\end{tabular}

Setelah melakukan penghitungan pada tabel diatas maka selanjutnya hasil dari perhitungan diatas tersebut dituangkan pada diagram sebab akibat (Fish Bone) seperti gambar berikut: 


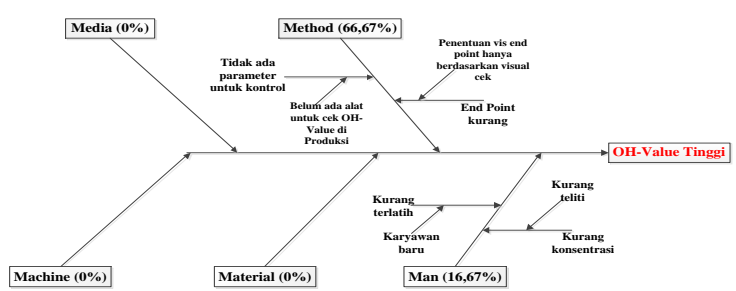

Gambar fishboneOH-Value tinggi

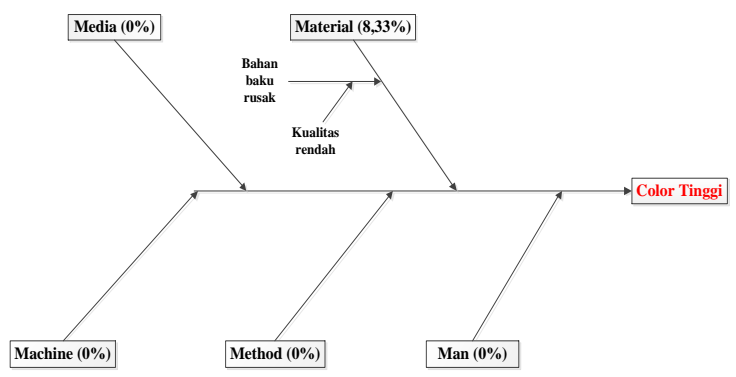

Gambar fishboneColor tinggi

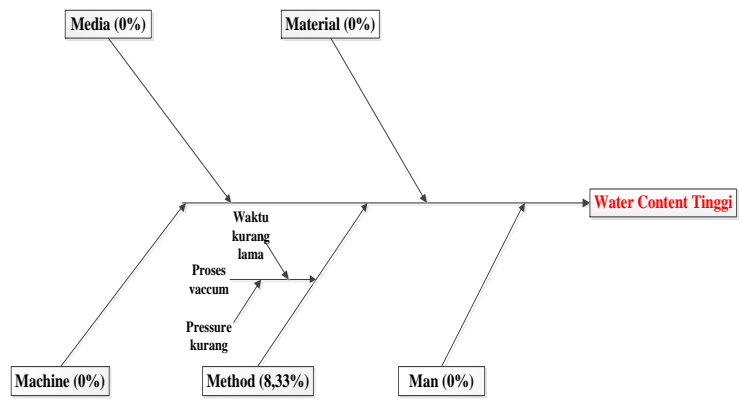

Gambar fishboneWater Content tinggi

Dari tabel dan diagram sebab akibat diatas, dapat diketahui bahwa faktor penyebab kecacatan tertinggi ada pada unsur Method, yaitu sebesar 75\%. Methoddapat menjadi penyebab kecacatan hasil pembuatan resin $A B C$ dikarenakan beberapa faktor, yaitu:

1. Tidak/belum adanya parameter untuk kontrol $\mathrm{OH}$-Value saat proses pembuatan resin $A B C$ sehingga menyulitkan operator untuk menentukan endpoint yang tepat sebelum cooling karena produksi tidak mempunyai alat untuk cek $\mathrm{OH}$ value.
2. Endpoint viskositas kurang juga merupakan salah satu penyebab $\mathrm{OH}$-Value menjadi tinggi karena penentuan endpoint viskositas menggunakan viskometer gardner yang pengecekannya adalah secara visual sehingga persepsi masingmasing operator pasti berbeda.

Faktor kedua penyebab kecacatan adalah Man, yaitu sebesar 16,67\%. Manusia dapat menjadi penyebab kecacatan pembuatan resin $A B C$ dikarenakan beberapa faktor, antar lain:

1. Karyawan bekerja kurang konsentrasi, hal ini sering menyebabkan ketelitian pekerjaan karyawan menjadi berkurang.

2. Karyawan belum memiliki skill/kemampuan yang cukup karena karyawan tersebut merupakan karyawan baru yang masih perlu bimbingan dan belajar.

Faktor ketiga penyebab kecacatan adalah Material, yaitu sebesar 8,33\%. Penyebabnya adalah kurangnya kontrol terhadap penanganan bahan baku yang akan dipakai untuk produksi. Karena ada beberapa jenis bahan baku yang perlu penanganan khusus sebelum dipastikan bahan baku itu layak pakai. Dari tiga faktor itulah penyebab dominan terjadinya kecacatan pada proses pembuatan resin $A B C$.

\subsection{Tahap Improve}

Pada tahapan ini yang dilakukan adalah menetapkan rencana-rencana tindakan untuk melaksanakan peningkatan kualitas menggunakan metode Six Sigma, berdasarkan 5W-1H (WHAT-tujuan utama, WHYalasan, WHERE-lokasi, WHEN-waktu, WHOorang, HOW-metode). Rencana tindakan/ usulan-usulan pada faktor man, material, method untuk masing-masing jenis kecacatan dapat dilihat pada beberapa tabel berikut: 
a. Tabel perbaikan masalah $\mathrm{OH}$-Value tinggi prinsip $5 \mathrm{~W}-1 \mathrm{H}$

\begin{tabular}{|c|c|c|}
\hline Jenis & $5 W-1 H$ & Deskripsi Rencana Perbaikan \\
\hline $\begin{array}{l}\text { Tujuan } \\
\text { utama }\end{array}$ & $\begin{array}{l}\text { What } \\
\text { (Apa) }\end{array}$ & $\begin{array}{l}\text { Menetapkan prosedur kerja bagi karyawan } \\
\text { bagian produksi }\end{array}$ \\
\hline $\begin{array}{c}\text { Alasan } \\
\text { Kegunaan }\end{array}$ & $\begin{array}{c}\text { Why } \\
\text { (Mengapa) }\end{array}$ & $\begin{array}{l}\text { Agar proses produksi sesuai dengan prosedur } \\
\text { kerja yang telah ditetapkan sehingga } \\
\text { menghasilkan produk yang sesuai spesifikasi }\end{array}$ \\
\hline Lokasi & $\begin{array}{l}\text { Where } \\
\text { (Dimana) }\end{array}$ & $\begin{array}{l}\text { Dilaksanakan di PT. Pardic Jaya Chemicals, } \\
\text { tepatnya di ruang produksi dan ruang untuk } \\
\text { pelatihan karyawan }\end{array}$ \\
\hline $\begin{array}{l}\text { Sekuens } \\
\text { (Urutan) }\end{array}$ & $\begin{array}{l}\text { When } \\
\text { (Kapan) }\end{array}$ & Pada saat stop proses produksi (dayshift) \\
\hline Orang & $\begin{array}{l}\text { Who } \\
\text { (Siapa) }\end{array}$ & $\begin{array}{l}\text { Tanggung jawab diserahkan kepada kepala } \\
\text { bagian produksi }\end{array}$ \\
\hline Metode & $\begin{array}{c}\text { How } \\
\text { (Bagaimana) }\end{array}$ & $\begin{array}{l}\text { 1. Melakukan percobaan penentuan endpoint } \\
\text { menggunakan viskometer Cone \& Plate } \\
\text { 2. Standarisasi hasil percobaan } \\
\text { 3. Memberikan pelatihan kepada karyawan } \\
\text { agar dapat menghasilkan produk yang baik }\end{array}$ \\
\hline
\end{tabular}

b. Tabel perbaikan masalah Water Content tinggi prinsip $5 \mathrm{~W}-1 \mathrm{H}$

\begin{tabular}{|c|c|c|}
\hline Jenis & $5 \mathrm{~W}-1 \mathrm{H}$ & Deskripsi Rencana Perbaikan \\
\hline $\begin{array}{l}\text { Tujuan } \\
\text { utama }\end{array}$ & $\begin{array}{l}\text { What } \\
\text { (Apa) }\end{array}$ & $\begin{array}{l}\text { Menetapkan prosedur kerja bagi karyawan } \\
\text { bagian produksi }\end{array}$ \\
\hline $\begin{array}{c}\text { Alasan } \\
\text { Kegunaan }\end{array}$ & $\begin{array}{c}\text { Why } \\
\text { (Mengapa) }\end{array}$ & $\begin{array}{l}\text { Agar proses produksi sesuai dengan prosedur } \\
\text { kerja yang telah ditetapkan sehingga } \\
\text { menghasilkan produk yang sesuai spesifikasi }\end{array}$ \\
\hline Lokasi & $\begin{array}{l}\text { Where } \\
\text { (Dimana) }\end{array}$ & $\begin{array}{l}\text { Dilaksanakan di PT. Pardic Jaya Chemicals, } \\
\text { tepatnya di ruang produksi dan ruang untuk } \\
\text { pelatihan karyawan }\end{array}$ \\
\hline $\begin{array}{l}\text { Sekuens } \\
\text { (Urutan) }\end{array}$ & $\begin{array}{l}\text { When } \\
\text { (Kapan) }\end{array}$ & Pada saat proses produksi \\
\hline Orang & $\begin{array}{l}\text { Who } \\
\text { (Siapa) }\end{array}$ & $\begin{array}{l}\text { Tanggung jawab diserahkan kepada kepala } \\
\text { bagian produksi }\end{array}$ \\
\hline Metode & $\begin{array}{c}\text { How } \\
\text { (Bagaimana) }\end{array}$ & $\begin{array}{l}\text { 1. Menambah waktu holding vaccum dengan } \\
\text { asumsi dapat mengambil kadar air yang } \\
\text { tertinggal saat akhir reaksi } \\
\text { 2. Standarisasi petunjuk kerja } \\
\text { 3. Memberikan pelatihan kepada karyawan } \\
\text { agar dapat menghasilkan produk yang baik }\end{array}$ \\
\hline
\end{tabular}

Tabel perbaikan masalah Color tinggi prinsip 5W-1H

\begin{tabular}{|c|c|l|}
\multicolumn{1}{c|}{ Tabel perbaikan masalah Color tinggi prinsip 5W-1H } \\
\hline Jenis & $\mathbf{5 W - 1 H}$ & \multicolumn{1}{|c|}{ Deskripsi Rencana Perbaikan } \\
\hline $\begin{array}{c}\text { Tujuan } \\
\text { utama }\end{array}$ & $\begin{array}{c}\text { What } \\
\text { (Apa) }\end{array}$ & $\begin{array}{l}\text { Menentukan bahan baku untuk resin ABC } \\
\text { secara tepat dan berkualitas }\end{array}$ \\
\hline $\begin{array}{c}\text { Alasan } \\
\text { Kegunaan }\end{array}$ & $\begin{array}{c}\text { Why } \\
\text { (Mengapa) }\end{array}$ & $\begin{array}{l}\text { Agar bahan baku sesuai dengan standar yang } \\
\text { telah ditetapkan perusahaan sehingga } \\
\text { menghasilkan produk yang sesuai spesifikasi }\end{array}$ \\
\hline Lokasi & $\begin{array}{c}\text { Where } \\
\text { (Dimana) }\end{array}$ & $\begin{array}{l}\text { Dilaksanakan di PT. Pardic Jaya Chemicals, } \\
\text { tepatnya di bagian penerimaan barang }\end{array}$ \\
\hline Sekuens & When \\
(Urutan) & Kapan) & Pada saat bahan baku dikirim oleh supplier \\
\hline Orang & $\begin{array}{c}\text { Who } \\
\text { (Siapa) }\end{array}$ & $\begin{array}{l}\text { Tanggung jawab diserahkan kepada bagian } \\
\text { quality control (penerimaan RM) }\end{array}$ \\
\hline Metode & How & $\begin{array}{l}\text { Mengadakan penjelasan tentang pentingnya } \\
\text { pemeriksaan bahan baku terlebih dahulu agar } \\
\text { memudahkan kontrol bahan baku yang akan } \\
\text { dipakai proses saat produksi, menetapkan } \\
\text { standar kualitas bahan baku }\end{array}$ \\
\hline
\end{tabular}

\subsection{TahapControl}

Rencana tindakan perbaikan yang dilakukan di PT. Pardic Jaya Chemicals akan dilaksanakan dalam jangka waktu satu tahun sehingga dapat mencapai target yang diinginkan perusahaan. Target yang ingin dicapai perusahaan yaitu mengurangi produk offgrade/outspec tidak lebih dari $1 \%$ dari jumlah produksi yang dihasilkan. Setelah melaksanakan rencana tindakan, perlu adanya perencanaan yang berupa alat kontrol untuk mengetahui apakah ada peningkatan kualitas pembuatan resin ABC. Tabel untuk mengontrol perencanaan yang telah dilakukan dapat dilihat pada tabel berikut ini:

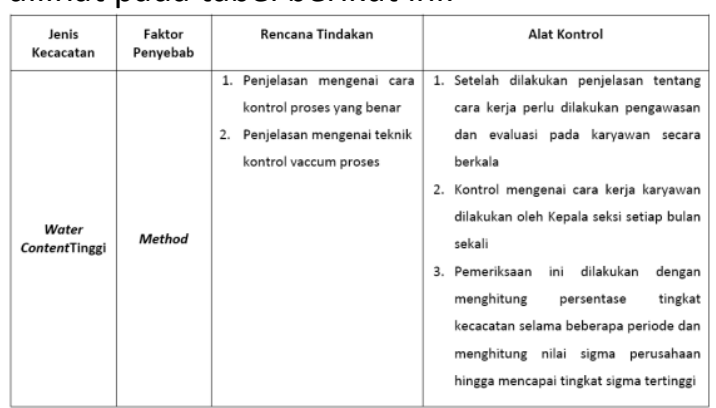




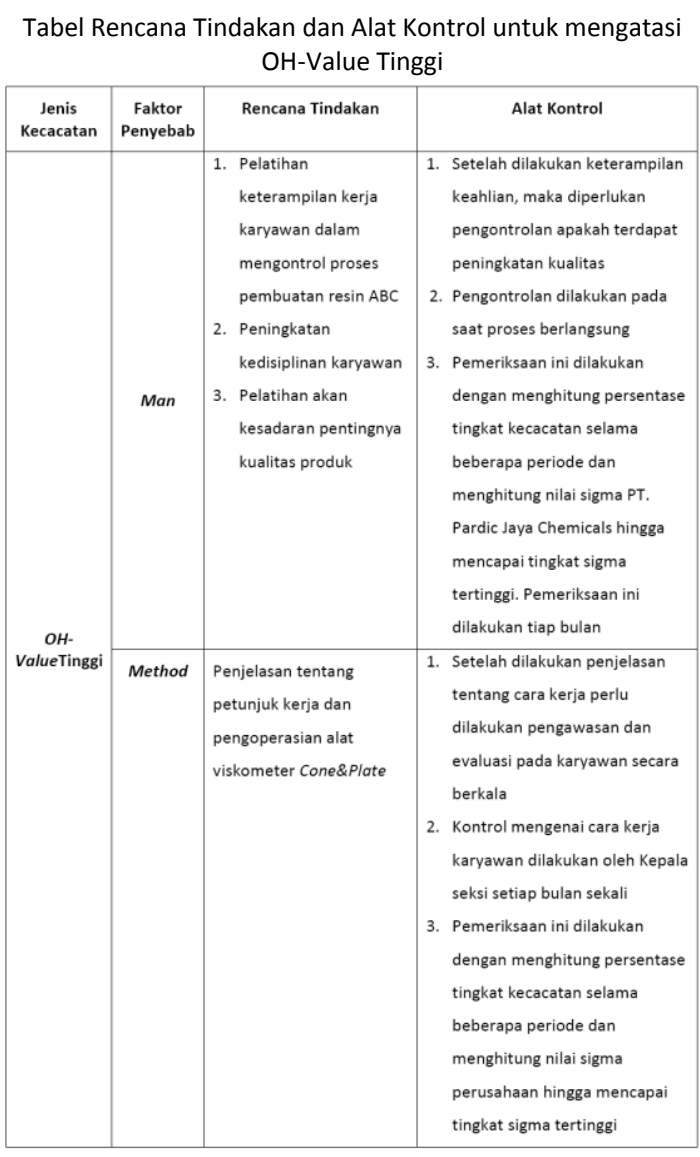

Tabel rencana Tindakan dan Alat Kontrol untuk mengatasi Water Content Tinggi

\begin{tabular}{|c|c|c|c|}
\hline $\begin{array}{c}\text { Jenis } \\
\text { Kecacatan }\end{array}$ & $\begin{array}{c}\text { Faktor } \\
\text { Penyebab }\end{array}$ & Rencana Tindakan & Alat Kontrol \\
\hline ColorTinggi & Material & $\begin{array}{l}\text { 1. Pemeriksaan yang } \\
\text { lebih efektif terhadap } \\
\text { bahan baku sebelum } \\
\text { proses produksi } \\
\text { 2. Penggunaan bahan } \\
\text { baku yang baik (tidak } \\
\text { melebihi shelflife / } \\
\text { kadaluwarsa) }\end{array}$ & $\begin{array}{l}\text { 1. Pengawasan dan } \\
\text { pengevaluasian kualitas } \\
\text { bahan baku dari supplier } \\
\text { pada saat barang tiba } \\
\text { 2. Pemeriksaan ini } \\
\text { dilakukan dengan } \\
\text { menghitung persentase } \\
\text { tingkat cacat beberapa } \\
\text { periode dan menghitung } \\
\text { nilai sigma perusahaan } \\
\text { hingga mencapai tingkat } \\
\text { sigma tertinggi }\end{array}$ \\
\hline
\end{tabular}

Rencana hasil tindakan diatas perlu dilakukan untuk peningkatan kualitas pembuatan resin $A B C$. Hal-hal yang perlu diperhatikan oleh PT. Pardic Jaya Chemicals dalam mengontrol semua rencana tindakan yang telah dilaksanakan adalah sebagai berikut:
1. Secara berkala (setiap 1 atau 2 bulan sekali) menghitung data hasil pembuatan resin $A B C$ yang cacat kemudian menghitung persentase tingkat kecacatannya.

2. Mencari potensial penyebab timbulnya kecacatan pembuatan resin $A B C$.

3. Menghitung DPMO dan nilai sigma untuk melihat peningkatan nilai sigma, dan seterusnya dilakukan perhitungan untuk dapat mencapai level 6 sigma dengan melebihi pencapaian sigma level sebesar 3,46 dan DPMO sebesar 25514,4. Setelah peningkatan kualitas six sigma berhasil, maka hasil-hasil yang telah tercapai dari tindakan peningkatan kualitas harus distandarisasi dan didokumentasikan.

\section{KESIMPULAN \& SARAN}

\subsection{Kesimpulan}

Dari hasil analisis penelitian yang telah dilakukan dapat disimpulkan bahwa perusahaan PT. Pardic Jaya Chemicals sampai sekarang masih belum menerapkan six sigma secara keseluruhan karena memang metode six sigma belum dipakai di PT. Pardic Jaya Chemicals. Namun metode six sigma dapat dipakai sebagai metode pembanding untuk improvement yang lebih baik. Untuk penerapan konsep secara sederhana dapat dikatakan bahwa perusahaan belum mampu mencapai target yang telah ditetapkan yaitu tidak lebih $1 \%$ produk cacat dari jumlah produksi perbulan. Hal ini terjadi karena perusahaan belum melakukan program perencanaan six sigma secara keseluruhan. Kesimpulannya adalah sebagai berikut:

1. Berdasarkan data produksi yang diperoleh dari PT. Pardic Jaya Chemicals diketahui jumlah produksi resin $A B C$ dari bulan Januari sampai September 2014 adalah sebanyak 396 item yang diperiksa dengan jumlah item cacat terjadi 12 item. Berdasarkan perhitungan, PT. Pardic Jaya Chemicals memiliki tingkat 
sigma 3,46 dengan kemungkinan 25514,4 untuk sejuta produksi (DPMO). Kapabilitas proses yang dicapai untuk masing-masing item yang masih terdapat kecacatan didalamnya adalah sebagai berikut Cp\&CpkOH-Value 1,20 \& 0,97 . Cp\&Cpkwatecontent $1,85 \& 0,83$. Sedangkan Cp\&Cpkcolor 2,26 \& 2,18. $\mathrm{Hal}$ ini tentunya menjadi sebuah kerugian yang sangat besar apabila tidak ditangani sebab semakin banyak produk yang gagal dalam proses produksi tentunya mengakibatkan pembengkakan biaya produksi. Jadi secara prinsip, six sigma dapat diterapkan untuk merencanakan pengendalian kualitas.

2. Jenis-jenis kerusakan yang sering terjadi pada produksi resin $A B C$ yaitu disebabkan karena $\mathrm{OH}$-Valuetinggi sebanyak 10 kali, watercontent tinggi sebanyak 1 kali, serta jenis cacat berupa color tinggi sebanyak 1 kali. Atau dengan kata lain CTQ (CriticaltoQuality) yang terjadi adalah $83,33 \%$ adalah $\mathrm{OH}$-Value tinggi, $8,33 \%$ watercontent tinggi, dan 8,33\% adalah color tinggi. Faktor penyebab $16,67 \%$ pada faktor man\& $66,67 \%$ pada faktor methoduntuk $\mathrm{OH}$-Value. Faktor penyebab pada faktor method8,33\% untukwatercontent, dan faktor penyebab pada faktor material $8,33 \%$ untuk color.

3. Six sigma merupakan metode dan konsep yang tepat untuk dipadukan dengan sistem Total Quality Control yang selama ini sudah diterapkan di PT. Pardic Jaya Chemicals karena secara detail bisa diaplikasikan untuk mencari penyebab defect/cacat yang terjadi hingga menghitung tingkat kemungkinan kecacatan setiap sejuta peluang serta melakukan improvisasi terhadap permasalahan defect yang sering terjadi.

Pada tahap akhir yaitu control, dilakukan rencana tindakan dan alat kontrolnya pada masing-masing kecacatan. Rencana tindakan- nya adalah berupa pelatihan ketrampilan karyawan dalam proses produksi resin $A B C$, peningkatan kedisiplinan karyawan, pelatihan karyawan untuk penggunaan alat baru. Sedangkan alat kontrol diperlukan untuk dapat mengetahui bahwa terjadi peningkatan kualitas atau tidak.

\subsection{Saran}

Saran yang dapat diberikan kepada PT. Pardic Jaya Chemicals adalah perusahaan perlu menerapkan rencana pengendalian kualitas sebelum melakukan produksi yaitu dengan cara:

1. Perusahaan harus dapat memberikan pengarahan kepada karyawannya tentang pentingnya kualitas produk resin $A B C$ dan meningkatkan disiplin kerja karyawannya.

2. Pimpinan Produksi harus sering melakukan kontrol terhadap semua hal yang menyangkut proses produksi khususnya pada tahapan analisa.

3. PT. Pardic Jaya Chemicals hendaklah lebih memperketat standar kualitas bahan baku yang nantinya akan dijadikan patokan untuk proses produksi.

4. Perusahaan harus dapat memberikan pelatihan kepada karyawan agar dapat menghasilkan produk yang berkualitas.

5. Pimpinan harus dapat membuat peningkatan pada kinerja para karyawan dengan cara menciptakan lingkungan kerja yang kondusif.

\section{DAFTAR PUSTAKA}

Yamit, Z. (2013). Manajemen Kualitas Produk \& Jasa. Yogyakarta: Ekonisia.

Evans, J.R. \& Lindsay, W.M. (2007). Pengantar Six Sigma AnIntroductionto Six Sigma \& Process Improvement. Singapore: South Western.

Pande, P.S., Neuman, R.P., \& Cavanagh, R.R. 
(2000). The Six Sigma Way. NewYork: McGraw-HillCompanies.

Hendradi, C.T. (2006). Statistik Six Sigma dengan Minitab. Yogyakarta: Andi Offset.

Pzydek, T. (2003).The Six Sigma Handbook. New York: McGraw-HillCompanies.

(Dari Buku)

Sudianto, M.D. (2008). Penggunaan Metode Six Sigma dalam Perencanaan Pengendalian Kualitas pada U.D.Global Info Media di Ungaran, Skripsi, Jurusan Manajemen FE Universitas Katholik Soegijapranata, Semarang

(Dari Skripsi)

Vitho dkk. (2013). Aplikasi Six Sigma untuk menganalisis faktor-faktor penyebab kecacatan produk Crumb Rubber SIR 20 pada PT. XYZ, DMAIC-FMEA, Kecacatan kadar PRI sebesar 70,42\%.

Hariri dkk. (2013). Penerapan metode Six Sigma sebagai upaya perbaikan untuk mengurangi Packdefect susu Greenfields (Studi kasus pada PT. Greenfield Malang), DMAIC-FMEA, RPN terbesar pada mesin filling yaitu 320. 